\title{
Potential Cost Avoidance of Adverse Drug Reactions Prevention in Outpatient Pharmacy Department Ramathibodi Hospital Thailand
}

\author{
Nia Kurnia Sholihat ${ }^{1,2}$, Wasin Chimsawat ${ }^{2,3}$ \\ ${ }^{1}$ Department of Pharmacy, Faculty of Health Sciences, Universitas Jenderal Soedirman, Purwokerto, Indonesia \\ ${ }^{2}$ Faculty of Pharmacy, Mahidol University, Bangkok, Thailand (2' affiliation at time of study) \\ ${ }^{3}$ Pharmacy Department, Ramathibodi Hospital, Bangkok, Thailand \\ Korespondensi: Nia Kurnia Sholihat \\ Email: nia_sholihat@yahoo.com
}

\begin{abstract}
Pharmacists' intervention in hospital setting is very beneficial both in patients' clinical outcome and economic aspect, in terms of cost avoidance due to adverse drug reactions. This study was conducted to calculate cost avoidance of adverse drug reactions (ADR) prevention in outpatient pharmacy department in Ramathibodi Hospital Thailand. A retrospective database review of hospital pharmacy interventions preventing adverse drug reaction was conducted at second floor pharmacy unit, SomdechPhraDebaratana Medical Center, Ramathibodi hospital between 1 July 2013 and 31 December 2013. Potential cost avoidance of ADR was calculated using diagnosis-related groups (DRG's) data. Results showed that the detection of ADR was $0.239 \%$. The most frequent ADR came from Penicillin group was accounted for 32.4\% of total case. The estimated cost avoidance generated during July-December 2013 was Thai Baht (THB) 592,320 to THB 1,257,428 (USD 19,278 to USD 40,925, value 2013). It can be concluded that hospital pharmacists positively impacted on economic benefit of patients by providing ADR detection. More complete data are needed to get a better results of a real cost avoidance of ADR prevention.
\end{abstract}

Keywords: cost avoidance; adverse drug reaction; hospital; pharmacists 


\section{Introduction}

Definition of adverse drug reaction (ADR) according to world health organization (WHO) is "a response to a drug that is noxious and unintended and occurs at doses normally used in man for the prophylaxis, diagnosis or therapy of disease, or for modification of physiological function". The latest definition of ADR from Edwards and Aronson is "an appreciably harmful or unpleasant reaction, resulting from an intervention related to the use of a medicinal product, which predicts hazard from future administration and warrants prevention or specific treatment, or alteration of the dosage regimen, or withdrawal of the product" [1].

The incidences of serious ADR ranged from 6.7\%-26.1\% [2-7]. A meta-analysis study from Lazarou et al. reported the overall incidence of serious ADR of hospitalized patients was $6.7 \%$. This was found to be extremely high and more dangerous than in outpatients [2]. A study from Bennett et al. showed the incidence was $7.2 \%$ (5.9\% of 85 surgical patients and $9.0 \%$ of 67 medical patients) [3]. Another study showed that the overall incidence of ADRs among hospitalized children was $9.53 \%$ and was a significant public health issue [4]. Another issue is $3 \%$ of the admissions were related to ADRs. In addition, $6.6 \%$ of hospitalized patients had significant ADRs. Between 5 and $9 \%$ of hospital costs were related to ADRs. Point prevalence of ADRs at admission was $3 \%$, incidence rate in hospital was 5.6/1000 patient-days [6]. The incidence of fatal adverse drug reactions in hospitalized patients has been estimated to be approximately $5 \%$ and $3 \%$ of it were suspected to have died from fatal ADRs [7]. The biggest number incidence of ADR was presented by Lagnaoui et al. They found 26.1\% ADRs occurred of all admissions [5].

Adverse drug reactions known as cause of highly cost of medical expenditures. A study from South India showed the total cost incurred in managing all the reported ADRs was Rs 76564 (US\$ 1595) with an average cost of Rs 690 (US\$ 15) per ADR [8]. Increased ADR-induced costs from hospitalized patients in a cardiovascular hospital in France costs Euro 4150 per ADR [9]. It means if ADR can be prevented, it can save a huge amount of money. A study from Goettler et al. showed cost of admission due to ADR was 1050 million DM per year in Germany. Preventability of ADR from previous ADR revealed about $30 \%$ of all ADRs to be preventable. With regard to Germany this means that 350 million DM per year could be saved by preventing adverse drug reactions [10]. The cost of ADRs leading to hospitalization in France by a study from Lagnaoui et al. was estimated at Euro 11,357 per hospital bed per year. Eighty percent of ADRs could be considered preventable [5].

One of roles of hospital pharmacist is to prevent adverse drug reactions (ADR) through clinical pharmacy services. One study from Kucukarslan et al. showed the rate of preventable adverse drug events (ADE) by pharmacist participation with the medical rounding team was reduced significantly by about 78\% [11]. Another study from Murray et al. was shown pharmacist intervention can lower risk of ADE and medication errors in outpatients with cardiovascular disease [12].

Economic benefit on this service was shown in some studies. A study showed actual and potential cost avoidance totaled $\$ 54,730.56$. The pharmacist provided value-added services and contributed to decreased costs associated with care [13]. Another study from Lee showed the overall mean cost avoidance per recommendation of clinical pharmacy services at a Veteran Affairs medical center was $\$ 700$, and the mean total cost avoidance for all 600 recommendations was $\$ 420,155$. Pharmacist recommendations improved clinical outcomes and saved money [14]. Study from Westerlund et al. demonstrates that community pharmacy interventions in patient DRPs are most likely to lead to favourable clinical and economic outcomes. The potential societal cost savings extrapolated to Sweden at the national level were estimated at $€ 358$ million [15]. Review study from Lada and Delgado showed that most studies 
reported positive financial benefits of the clinical pharmacy service evaluated. In 16 studies, a benefit:cost ratio was reported by the authors or was able to be calculated by the reviewers (ranged from 1.7:1-17.0:1, median 4.68:1) [16].

Even though many studies reported economic benefit of hospital pharmacy services, this kind of benefit of cost avoidance where specifically conducted in outpatient department Ramathibodi Hospital Thailand has not been proven. Therefore, the objective of this study was to calculate cost avoidance of ADR prevention in outpatient pharmacy department in Ramathibodi Hospital Thailand.

\section{Method}

\subsection{Study design}

This study was a retrospective, based on database review of hospital pharmacy interventions preventing ADR conducted at second floor pharmacy unit, Somdech Phra Debaratana Medical Center (SDMC), Ramathibodi hospital Thailand between July 1, 2013 and December 31, 2013.

\subsection{Setting and patient population}

This study was conducted at the second-floor pharmacy outpatient department (OPD) unit of Somdech Phra Debaratana Medical Center (SDMC), the Faculty of Medicine Ramathibodi Hospital Thailand, a university hospital of Mahidol University, which has three principal buildings to serve more than 5,000 out-patients per day. Somdech Phra Debaratana Building (royally opened by Somdech Phra Debaratana on August 14, 2011) is the largest and newest building, serves as the most excellent service complex for thousands of out-patients of all types of healthcare coverage per day.

This study targeted toward outpatients in the second-floor pharmacy unit, Somdech Phra Debaratana Medical Center which composed of 5 clinics as follows 1) Surgery OPD; 2) Orthopedics OPD; 3) Eye, Ear, Nose, and Throat (EENT) OPD;

4) Dermatology OPD; and 5) Pain clinic.

\subsection{Data collection}

The data were collected by pharmacists from spontaneous DRPs report at hospital which focused on adverse drug prevention. The information collected were about the adverse drug reactions occurred, and activities performed by pharmacists and physicians.

Patient who has been suspected drug related problems (DRPs), following classification by van den Bemt, would be notified to the physician by blue paper and confirmed the order correctly before patient received the medicine [17]. When the suspected DRPs was notified or detected from the process, pharmacist would input the detail in Microsoft Excel program. All activities regarding entering interventions were voluntary. We defined potential cost avoidance as the cost of treatment that may have been incurred if an intervention had not occurred.

\subsection{Data analysis}

Data were analyzed by using Excel program and the findings were presented in 2 areas:

1) Total number of ADRs preventing by pharmacist. We simply calculated the number of ADRs detection by pharmacist.

2) The cost of treating ADR complications if pharmacists could not detect it. Cost included in this study was direct medical cost. ADRs from each drug were derived from Spontaneous ADR report by Thai Food and Drug Administration (Thai FDA) [18]. We estimate potential ADRs that may have occurred by range it from mild to severe ADR from that report. Mild ADR was defined as ADR that cause the least impact to patient, e.g. rash and pruritus; and severe ADR was defined as ADR that cause harm to patient, e.g. StevensJohnsons syndrome and erythema multiforme. Mild and severe ADR were also known from the relative weight of the severity of ADR, range from 0 to 1 . Then, we determined how much potential cost avoidance by using cost of each treatment from diagnosis-related group (DRG's) data. In DRG, one relative weight was accounted THB 9,600. To estimate the uncertainty of ADRs 
that may have occurred; we conducted a simple sensitivity analysis to range the calculation from mild ADR case to severe ADR case.

Total cost avoidance would be the result of the number of detection of ADR multiply by relative weight of severity of ADR. All costs were presented in Thai Baht year 2013 (USD $1=$ THB 30.725 , value 2013).

\section{Result}

During 1 July-31 December 2013, we found 223 events of ADR that could be prevented by pharmacist of 93,303 prescriptions. The detection of ADR was $0.239 \%$. Total number of pharmacist was 10 , divided into 7 full timer pharmacists (08.30-16.30) and 3 part timer pharmacists (10.00-15.00). Average cases of ADR every month was 36.8 cases and one pharmacist could prevent 22 cases in average for 6 months and saved THB 92,487.4.

Total cost avoidance of 223 events of ADR prevention was THB 592,320 in mild case and THB 1,257,428 in the worst case (Table 1). Average cost per incidence was THB 2,656.14 in mild case and THB 5,638.9 in severe case. Most of drugs which ADR were prevented in OPD Ramathibodi Hospital were antibiotics (Penicillin, Cephalosporin, Quinolone, and Sulfa group) and analgesic (Paracetamol, Ibuprofen, Meloxicam, Piroxicam, Naproxen). The other drugs were Coxib, muscle relaxant, and GABA. Penicillin group was accounted as the most frequent drug with total 72 cases. The incidence of Penicillin group was $32.58 \%$ of total case. Mild ADR varied from rash, to maculopapular (MP)-rash, angioedema, pruritus, and urticaria. Severe ADR also varied from Stevens-Johnsons syndrome, to erythema multiforme, dyspnea, and palpitation.

The bigger proportion of cost avoidance came from Amoxicillin $(\mathrm{N}=22)$ that was counted THB 135,759 in the worst case and THB 51,617 in mild case, followed by Amoxicillin \& clavulanate and Penicillin $\mathrm{V}$ each was accounted for THB 117,247 in the worst case and THB 44,579 in mild case. The trend of ADR prevention in 2013 was decreasing in the first four months but increasing afterwards (Figure 1). The least cases were reported in October ( $\mathrm{N}=17$ cases) and the most cases were reported in December ( $\mathrm{N}=65$ cases).

\section{Discussion}

Hospital pharmacists' intervention in outpatient department Ramathibodi Hospital had a positive impact on cost avoidance for preventing ADR events. They performed screening on the prescriptions and corrected the prescribing errors. We found 223 cases of ADR that pharmacists could prevent during 1 July-31 December 2013, with a range of cost avoidance from THB 592,320 to THB 1,257,428. One pharmacist could save THB 92,487.4in six months. Average cost per incidence was THB 2,656.14 in mild case and THB 5,638.9 in severe case. This cost seemed not so high when we compare to other study from Lada and Delgado [19] which was performed documentation of pharmacists' interventions in an emergency department and associated cost avoidance, they found between 1 September 2003 and 31 December 2003 cost avoidance during the study was determined to be $\$ 1,029,776$. Another findings from Galt [20] showed actual and potential cost avoidance in a Veterans Affairs Medical Center totaled

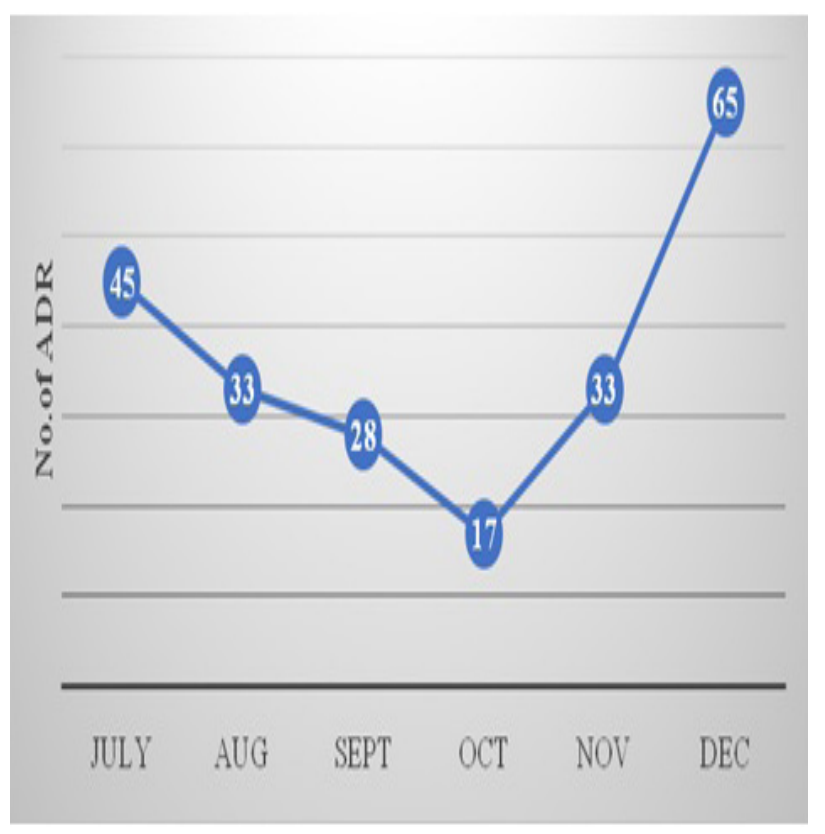

Figure 1. Number of ADR in each month 


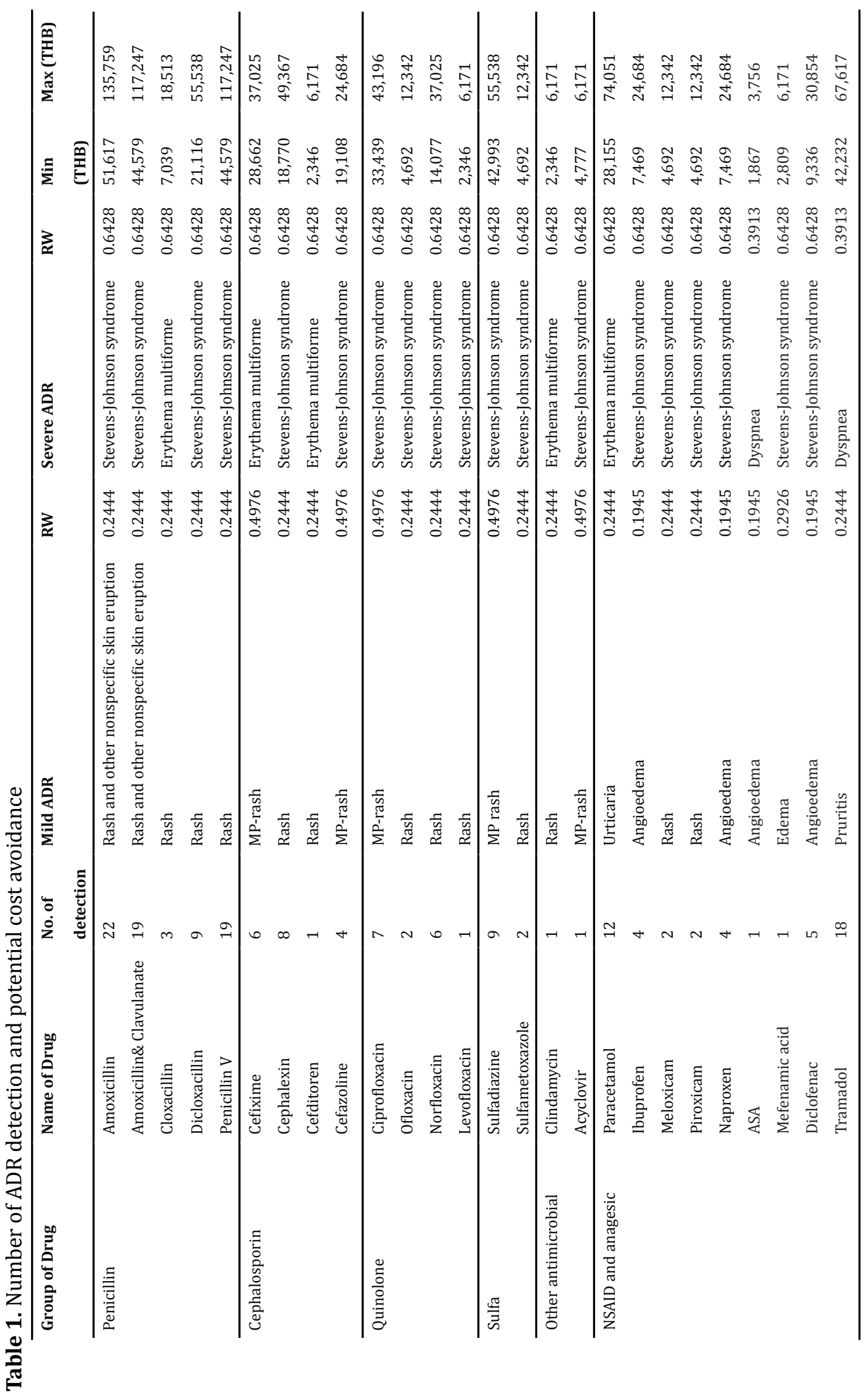




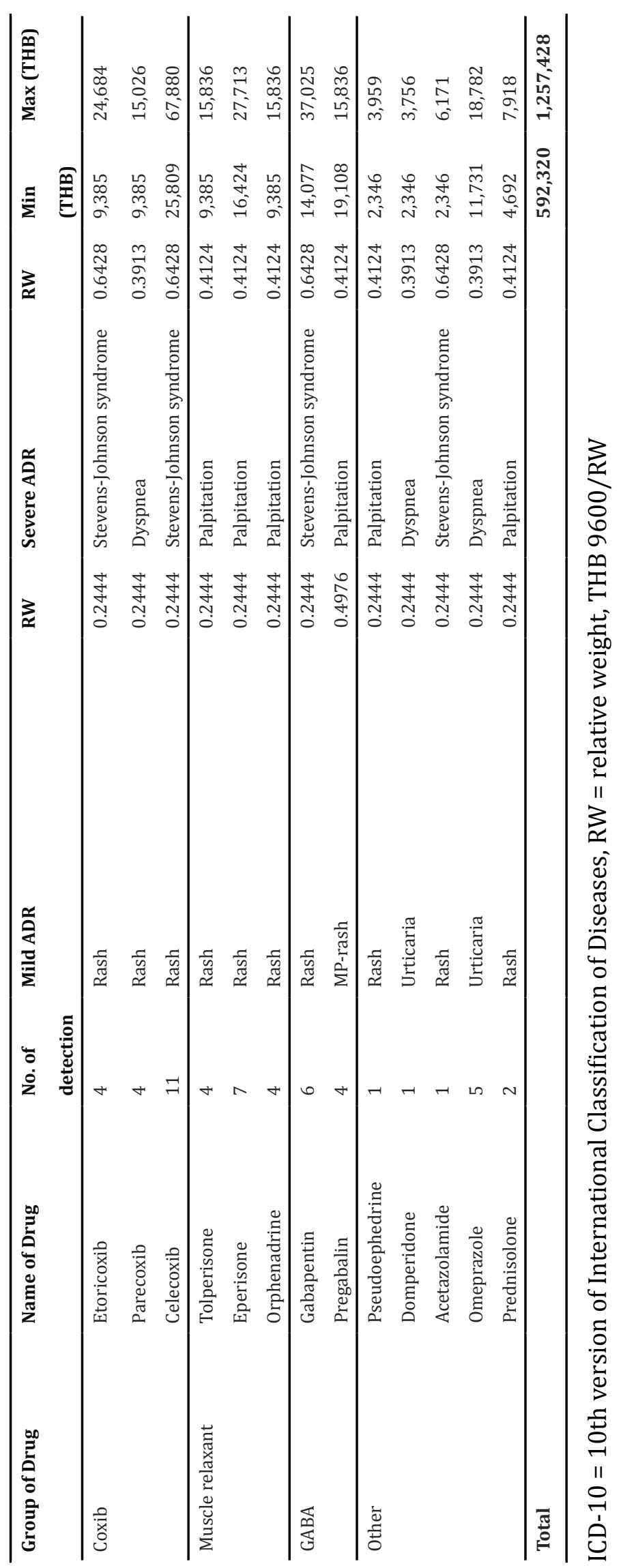


$\$ 54,730.56$. The differences of our result with the above study might be caused of the differences in the number patients and differences in presenting total cost avoidance. In Lada and Delgado's study, they extrapolated the cost into one year [19]. The pharmacist provided value-added services and contributed to decreased costs associated with care. Similar study from Woolley [21] evaluated potential cost avoidance of pharmacy students' intervention estimated potential total cost avoidance of $\$ 908,800$.

These findings may be caused of under reported data. The data was collected only from normal clinic which open from 08.30-16.30 only on the second floor of Somdech Phra Debaratana Medical Center building. The data from special clinic (16.30-21.00) and from other outpatient departments were not included in this study. The number of detection of ADR was $0.239 \%$. This was quite low if we compare to other studies where the incidence of serious ADR ranged from 6.7\%-26.1\% [2-7]. In our knowledge, there was no study exploring potential cost avoidance by pharmacist in outpatient department. Most study were performed in hospitalized patients $[6,9,13]$, showed the relationship of ADR and admission.

Our study had several limitations. Firstly, we collected data from some outpatient clinics only, so that generalizability to the other outpatient department should be made with cautions. Secondly, the limitation from the data itself. Due to retrospective way of this study, some data were loss (e.g. patients' name and hospital number) and some were incomplete. We suggested to the next study to perform study in prospective way or in experimental design to compare usual activities and pharmacists' interventions activities, such as dose adjustment, drug information to patient, patient education, etc.

The most frequent drug we found of ADR was in Penicillin group, such as Amoxicillin and Amoxicillin \& clavulanate. This might due to the number of usage of antibiotics in the hospital. Our findings showed that many events of ADR came from cross-reactivity of drugs in similar structure, such as beta-lactam antibiotics [22]. Physicians, the one who wrote prescriptions mostly did not aware of this kind of issue. Moreover, they were still prescribing in manual way (writing prescriptions on a paper). Pharmacist was also the one who responsible to key in information of drug allergy. Some data of allergy might be loss because of problem in connection between physician and pharmacist. Our suggestions were to implement electronic prescribing and to improve database systems. Information of drug allergy would be contained with possibility of cross-reactivity among drugs.

\section{Conclusion}

Hospital pharmacists positively impacted on economic benefit of patients by providing ADR detection. The estimated cost avoidance generated during 1 July-31 December 2013 was THB 592,320-THB 1,257,428 (USD 19,278-USD $40,925)$. More complete data needed to get a better results of real cost avoidance of ADR.

\section{Acknowledgements}

The authors are thankful to Pharmacy Unit Ramathibodi Hospital for providing data to our work. There is no conflict of interest in our study.

\section{References}

1. Edwards IR, Aronson JK. Adverse drug reactions: definitions, diagnosis, and management. The Lancet. 2000;356(9237):1255-9.

2. Lazarou J, Pomeranz BH, Corey PN. Incidence of adverse drug reactions in hospitalized patients: A meta-analysis of prospective studies. JAMA. 1998;279(15):1200-5.

3. Bennett B, Lipman A. Comparative study of prospective surveillance and voluntary reporting in determining the incidence of adverse drug reactions. American Journal of Health-System Pharmacy. 1977;34(9):931-6.

4. Impicciatore $\mathrm{P}$, Choonara I, Clarkson A, Provasi D, Pandolfini C, Bonati M. Incidence 
of adverse drug reactions in paediatric in/ out-patients: a systematic review and metaanalysis of prospective studies. British Journal of Clinical Pharmacology. 2001;52(1):77-83.

5. Lagnaoui R, Moore N, Fach J, Longy-Boursier $\mathrm{M}$, Bégaud B. Adverse drug reactions in a department of systemic diseases-oriented internal medicine: prevalence, incidence, direct costs and avoidability. E J Clin Pharmacol. 2000;56(2):181-6.

6. Moore N, Lecointre D, Noblet C, Mabille M. Frequency and cost of serious adverse drug reactions in a department of general medicine. British Journal of Clinical Pharmacology. 1998;45(3):301-8.

7. Wester K, Jönsson AK, Spigset O, Druid H, Hägg S. Incidence of fatal adverse drug reactions: a population based study. British Journal of Clinical Pharmacology. 2008;65(4):573-9.

8. Ramesh M, Pandit J, Parthasarathi G. Adverse drug reactions in a South Indian hospital-their severity and cost involved. Pharmacoepidemiol Drug Saf. 2003;12(8):687-92.

9. Bordet R, Gautier S, Le Louet H, Dupuis B, Caron J. Analysis of the direct cost of adverse drug reactions in hospitalised patients. $E J$ Clin Pharmacol. 2001;56(12):935-41.

10. Goettler M, Schneeweiss S, Hasford J. Adverse drug reaction monitoring--cost and benefit considerations. Part II: cost and preventability of adverse drug reactions leading to hospital admission. Pharmacoepidemiol Drug Saf. 1997;6 Suppl 3:S79-90. Epub 2004/04/10.

11. Kucukarslan SN, Peters M, Mlynarek M, Nafziger DA. PHarmacists on rounding teams reduce preventable adverse drug events in hospital general medicine units. Archives of Internal Medicine. 2003;163(17):2014-8.

12. Murray MD, Ritchey ME, Wu J, Tu W. EFfect of a pharmacist on adverse drug events and medication errors in outpatients with cardiovascular disease. Archives of Internal Medicine. 2009;169(8):757-63.

13. McMullin S, Hennenfent JA, Ritchie DJ, et al.
A prospective, randomized trial to assess the cost impact of pharmacist-initiated interventions. Archives of Internal Medicine. 1999;159(19):2306-9.

14. Lee AJ, Boro MS, Knapp KK, Meier JL, Korman NE. Clinical and economic outcomes of pharmacist recommendations in a Veterans Affairs medical center. American Journal of Health-System Pharmacy. 2002;59(21):20707.

15. Westerlund T, Marklund B. Assessment of the clinical and economic outcomes of pharmacy interventions in drug-related problems. Journal of Clinical Pharmacy and Therapeutics. 2009;34(3):319-27.

16. Schumock GT, Butler MG, Meek PD, Vermeulen LC, Arondekar BV, Bauman JL, et al. Evidence of the Economic Benefit of Clinical Pharmacy Services: 1996-2000. Pharmacotherapy: The Journal of Human Pharmacology and Drug Therapy. 2003;23(1):113-32.

17. van den Bemt P. Drug related problems: definitions and classification. EJHP Practice. 2005;11:16.

18. Center HPV. Spontaneous ADR report by Thai FDA. 2014 [14 January 2014]; Available from: http://thaihpvc.fda.moph.go.th/thaihvc/ Public/Webpage/main.jsp.

19. Lada P, Delgado JG. Documentation of pharmacists' interventions in an emergency department and associated cost avoidance. American Journal of Health-System Pharmacy. 2007;64(1):63-8.

20. Galt KA. Cost Avoidance, Acceptance, and Outcomes Associated with a Pharmacotherapy Consult Clinic in a Veterans Affairs Medical Center. Pharmacotherapy: The Journal of Human Pharmacology and Drug Therapy. 1998;18(5):1103-11.

21. Woolley AB, Berds CAt, Edwards RA, Copeland D, DiVall MV. Potential cost avoidance of pharmacy students' patient care activities during advanced pharmacy practice experiences. Am J Pharm Educ. 2013;77(8):164. Epub 2013/10/26. 
22. James CW, Gurk-Turner C. Cross-reactivity of beta-lactam antibiotics. Proc (Bayl Univ Med Cent). 2001;14(1):106-7. Epub 2005/12/22. 